\title{
A Discourse Analysis Approach to the Sluicing Conundrum*
}

\author{
Soo-Yeon Kim
}

Sejong University

\begin{abstract}
With a critical review of previous analyses on sluicing construction, this study points out problems with structural analyses on sluicing and demonstrates a way to retrieve putative sources for the elided portion in sluicing, minimizing the complexity of deriving sluicing constructions. This paper focuses on so called connectivity effects that constitute a prima facie piece of evidence of movement of the sluice out of a sentential constituent. Much work has been done to resolve the sluicing conundrum between the connectivity effect and absence of syntactic island violation. This paper argues that employing the Cooper style E-type pronoun in the derivation of the second conjunct of sluicing constructions can account for the conundrum without unnecessary complication of grammar. This paper also shows the necessity of considering relevant discourse that affects the acceptability of sluicing which can be represented as a continuum depending on the prominency of the correlate. Degraded acceptability of sluicing with implicit antecedents is from difficulties in parsing the sluice with non-prominent antecendent.
\end{abstract}

Keywords: ellipsis, sluicing, E-type anaphora, discourse activation, implicit antecedent, prominency, processing

\footnotetext{
* This work is supported by the National Research Foundation of Korea Grant funded by the Korean Government (NRF-2008-A00293).
} 
150 A Discourse Analysis Approach to the Sluicing Conundrum

\section{Introduction}

Ross (1969) discusses constructions called sluicing, where a whphrase in lieu of a complete interrogative sentence apparently represents an interpretation of a full sentence structure. The theoretical import of sluicing constructions lies in the fact that it is a representative example of linguistic phenomena where the fundamental correspondence between sound and meaning of human languages breaks down. Since then an extensive body of literature has been devoted to the study of sluicing with respect to what it is, how it is derived, and what it implies in linguistic theories.

Sluicing is a term coined by Ross (1969) to refer to a construction where an apparently fronted $w h$-expression appears in isolation with an interpretation of fully-fledged interrogative construction as demonstrated in (1):

(1) a. Someone called but I don't know who.

b. John is reading but I don't know what.

One of the central questions in research on sluicing is what kinds of representations are involved in the resolution and licensing of unpronounced parts in the second conjunct. There have been three general schools of analysis for sluicing depending on whether they believe the assumed material is present at some level of syntactic structure or not as in (2a-c). An overview of the study of sluicing is schematically represented in the following: 
(2)

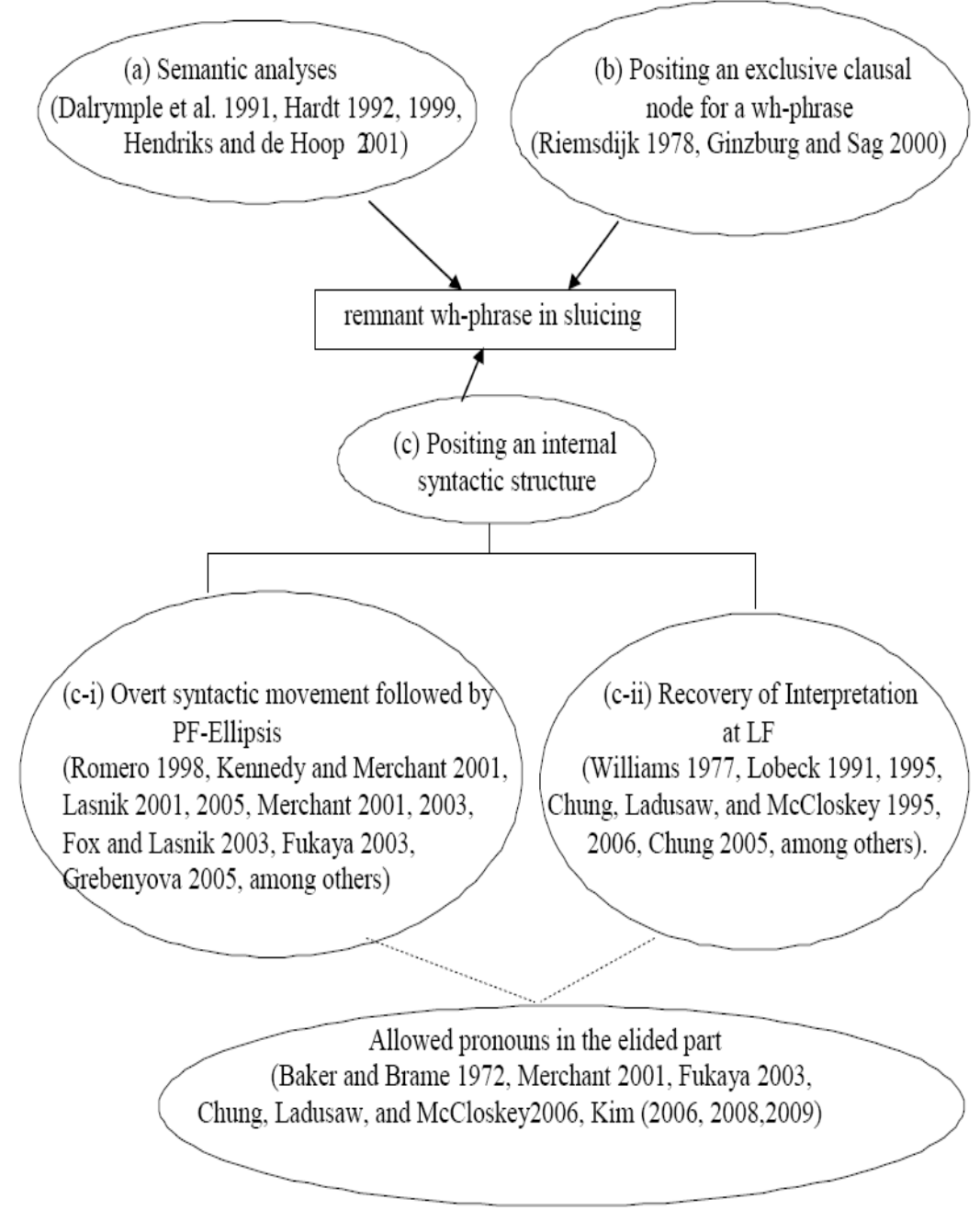

The analyses that this paper investigates are the ones that assume structures internal to the unpronounced site after the sluice as in 
152 A Discourse Analysis Approach to the Sluicing Conundrum

(2c). ${ }^{1}$ Despite the fact that a sluiced $w h$-expression constitutes the only overt material in the sluice, these analyses expect to find a complete interrogative construction based on interpretations of the sluice. Examples of this line of approach are (3) and (4):

(3) a. Someone called but I don't know [CP who [IP ealled ]]
b. John is reading but I don't know [CP what [IP John is
reading $t]]$

(4) a. Someone called but I don't know [CP who ${ }^{\mathrm{x}}$ [IP someone ${ }^{\mathrm{x}}$ called]]

b. John is reading but I don't know [CP what ${ }^{\mathrm{x}}$ [IP John is reading $\left.\left.t^{\mathrm{x}}\right]\right]$

One postulates syntactic derivation of the full construction including the sluice with a subsequent deletion of the part as in (3) and the other hypothesizes a general recovery mechanism as in (4). The former, which we call a PF-deletion analysis, assumes that sluicing is derived identically to fully-fledged $w h$-interrogatives involving $w h$-movement. The latter, called an LF-copying analysis, argues that there is no overt $w h$-movement but that sluicing is interpreted as such by copying at LF. Following $\operatorname{Kim}(2006,2008$, 2009), this paper assumes that the elided part of the sluicing has internal structure but that does not have to be syntactically the same as that of its antecedent clause. It not only provides cases that necessitate the E-type pronoun in sluicing but lessens the burden of grammar by reducing derivational mechanisms. This way of approaching the sluicing conundrum has the additional outcome of predicting the acceptability of antecedent-less sluicing cases.

\footnotetext{
${ }^{1}$ We refer to the stranded $w h$-expression in the second conjunct as the remnant or the sluice and the corresponding material to the remnant in the first conjunct as the correlate.
} 
This paper is organized as follows: Section 2 starts with the much-discussed observation on sluicing with introduction of the sluicing conundrum and reviews previous analyses that posit an identical structure of the second conjunct. Section 3 discusses local extraction in tandem with E-type anaphors to analyze interpretations of sluicing and suggests a way to resolve lack of island effects in sluicing. It also investigates whether a local extraction approach to sluicing is sufficient to reflect the connectivity effects. Section 4 investigates empirical limitations in the structure-based analyses and proposes additional effects of the local extraction approach to sluicing. It leads to the conclusion that consideration of the previous discourse not only matters but is a key to the degree of acceptability of sluicing sentences, especially when the antecedent of the sluice is implicit.

\section{The Sluicing Conundrum: Facts and Proposals}

Discussions on sluicing have a long history going back to Ross (1969). Since then much attention has been paid to its analysis, as it is situated at the center of two important phenomena in generative grammar, movement and ellipsis. As we can see in (6) and (7), the surface of sluicing is simple as it consists of a sole $w h$-interrogative (and optionally with a preposition), but there is a theoretical complication lurking beneath the simple surface:

(6) a. John likes someone but I don't know who.

b. Sally bought a book but I don't know which.

(7) a. A car is parked on the lawn - find out whose.

b. Sally's out hunting - guess what!

c. Jack called, but I don't know \{when/how/why/where from $\}$. 
154 A Discourse Analysis Approach to the Sluicing Conundrum

The remnants in the second conjunct of the sentences in (6) have their overt antecedents in the first conjunct. The antecedents of the remnants in (7), however, are implicit in that they do not appear overtly in the first conjunct. Sluing examples in (6) and (7) should be compared to their synonymous fully-fledged counterparts in (8) and (9):

(8) a. John likes someone but I don't know who(m) he likes.

b. Sally bought a book but I don't know which book she bought.

(9) a. A car is parked on the lawn - find out whose car is parked on the lawn.

b. Sally's out hunting - guess what she 's out hunting!

c. Jack called, but I don't know \{when/how/why/where from $\}$ he called.

In some form or another, sluicing appears to be found crosslinguistically in every language. The PF-deletion approach to sluicing, which is one of the predominant studies of sluicing, assumes that sluicing involved movement of a wh-phrase out of a sentential constituent like (8) and (9), followed by deletion of the constituent (Ross 1969, Chomsky and Lasnik 1993, Lasnik 2001, 2007, Merchant 2001, 2002, 2004, Fox 2000, Kennedy and Merchant 2000, Fox and Lasnik 2003, Fortin 2007 among others). Empirical support for the PF-deletion approach comes from "agreement properties" and so-called "connectivity effects" such as Case-matching effects, preposition stranding, and binding effects. Agreement properties of sluicing are illustrated in the following. Even when the sluice is plural as in (10a), agreement is invariably singular:

(10) a. We are supposed to work on some problems, but which problems isn't (*aren't) clear. 
b. We are supposed to work on some problems, but which problems we were supposed to work on isn't (*aren't) clear.

One of the main connectivity effects is represented in the Case of a sluice. In overtly Case marked languages such as German, the Case of a sluice is exactly the same morphological Case as what the Case of the $w h$-interrogative would have been in the full-fledged form:

(11) a. Er will jemandem schmeicheln, aber sie wissen nicht, he wants someone-Dat flatter but they know not $\left\{*^{*}\right.$ wer / *wen / wem $\}$. who-Nom who-Acc who-Dat 'He wants to flatter someone, but they don't know who.'

b. Er will jemandem schmeicheln, aber sie wissen nicht, he wants someone-Dat flatter but they know not $\left\{{ }^{*}\right.$ wer $/{ }^{*}$ wen / wem $\}$ er schemeicheln will. who-Nom who-Acc who-Dat he flatter wants 'He wants to flatter someone, but they don't know who he wants to flatter.'

According to the PF-deletion analysis, explored in detail in Merchant (2001), Case matching effects seem to be overwhelmingly pervasive in overtly Case marked languages such as German, Greek, Russian, Polish, Czech, Slovene, Finnish, Hindi, Hungarian, Basque, Turkish and Korean. It supports the claim that wh-movement actually takes place in the second conjunct followed by deletion of the rest of the clause except for the $w h$-phrase.

Another argument for the PF-deletion analysis is from Merchant (2001)'s generalization in (12), which involves preposition stranding under movement: ${ }^{2}$

\footnotetext{
${ }^{2}$ It is noteworthy that there have been claims that connectivity effects do not necessarily hold in every language. Malagasy, for instance, does not show Case
} 
156 A Discourse Analysis Approach to the Sluicing Conundrum

(12) A language L will allow preposition stranding under sluicing iff $\mathrm{L}$ allows preposition stranding under regular $w h$-movement.

Merchant (2001, 2003) provides relevant examples from 6 preposition stranding languages and 18 non-preposition stranding languages. Some of the examples are:

(13) a. Peter was talking with someone, but I don't know (with) who. (English)

b. Piet hat mei ien sprutsen, mar ik wyt net Piet has with someone talked but I know not (mei) wa.

with who (Frisian)

c. Per har snakket med noen, men jeg vet ikke Per has talked with someone but I know not (med) hvem. with who (Norwegian)

d. Peter har snakket med en eller anden, men jeg Peter has talked with one or another but I know ved ikke (med) hvem. not with who (Danish)

(14) a. I Anna milise me kapjon, alla dhe ksero the Anna spoke with someone but not I.know *(me) pjon. with who (Greek)

b. Anna hat mit jemandem gesprochen, aber ich Anna has with someone spoken but I weiß nicht, *(mit) wem.

know not with who (German)

matching and preposition stranding parallelism in sluicing (Postdam 2003). 
c. $\mathrm{Zi}$ hot mit emetsn geredt, over ikh veys nit she has with someone spoken but I know not *(mit) vemen. with who (Yiddish)

d. Anja govorila s kem-to, no ne znaju Anja spoke with someone, but not I.know *(s) kem. with who (Russian)

e. Anna je govorila $\mathrm{z}$ nekom, ampak ne vem Anna aux spoken with someone but not I.know *(s) koj.

with who (Slovene)

f. Anna e govorilas njakoj, no na znam Anna AUX spoken with someone but not I.know *(s) koj. with who (Bulgarian)

g. Ana je govorila sa nekim, ali ne znam Ana AUX spoken with someone but not I.know *(sa) kim. with who (Serbo-Croatian)

h. Ali ba kasi harf mi-zad, Ali with someone talk PROG-hit.3sg ? ama ne-mi-dan-am *(ba) ki. but not-PROG-know-I with who (Persian)

i. Dani katav le-mishehu, aval ani lo yode'a Dani wrote to-someone, but I not know *(le-)mi. to-who (Hebrew)

j. Ana-k norbait-ekin hitzegin zuen, baina ez Ana-ERG someone-with talk.to aux but not dakit nor-*(ekin). know who- with (Basque) 
158 A Discourse Analysis Approach to the Sluicing Conundrum

If a language allows preposition stranding under regular whmovement, a wh-interrogative with a stranded preposition can constitute a legitimate sluice as in (13). Likewise, if prepositions cannot be stranded in a given language, it is impossible for the sluice to appear with a stranded preposition as demonstrated in (14). If sluicing were derived without overt movement and subsequent deletion, the correlation shown above would remain mysterious.

Finally, binding of elements in the sluice is possible without any overt binder in the second conjunct of sluicing as presented in Lasnik (2001, 2005):

(15) a. Every linguist ${ }_{i}$ criticized some of his ${ }_{i}$ work, but I am not sure how much of his $\mathrm{s}_{\mathrm{i}}$ work.

b. Each of the linguists criticized some of the other linguists, but I am not sure how many of the other linguists.

Here again, without assuming overtly derived (and later deleted) binder of his and the other in the examples in (15), it is not easy to explain the given interpretation of the second conjuncts.

Based on the above mentioned empirical data, a large body of work has converged on the conclusion that there is a derivation of the full structure in the second conjunct, which is the same as the first one, and under the identity condition, the rest of the second conjunct other than the sluice gets deleted. This much seems to be clear as far as the above mentioned effects are concerned. However, when we compare the following two sets of sentences with completely opposite acceptability status, we can see there is a complication beneath the simple surface to be accounted for:

(16) a. (??) I believe the claim that he bit someone, but they don't know who.

b. * I believe the claim that he bit someone, but 
they don't know who I believe [the claim that he bit].

(17) a. (??) She kissed a man who bit one of my friends, but Tom doesn't realize which one of my friends.

b. * She kissed a man who bit one of my friends, but Tom doesn't realize which one of my friends she kissed [a man who bit].

(18) a. (??) That he'll hire someone is possible, but I won't divulge who.

b. * That he'll hire someone is possible, but I won't divulge who [that he'll hire] is possible.

(19) a. (??) Irv and someone were dancing together, but I don't know who.

b. *Irv and someone were dancing together, but I don't know who [Irv and] were dancing together.

When Ross (1969) discussed what he calls sluicing constructions, he also noticed that if the island forming nodes, which are represented as boldfaced brackets in (b) sentences above, do not appear in surface structure as in (a) sentences, island violation effects seem to result in less severe deviance. ${ }^{3}$ In fact, most recent studies on sluicing report that the acceptability status of sluicing sentences with apparent island violations is almost perfect (Merchant 2001, Chung et al 1995, Lasnik 2005 among others):

(20) a. They want to hire someone who speaks a Balkan

3 The judgments in parentheses are Ross's. We will discuss later that the acceptability status of the sluicing construction is not necessarily the same even when the assumed source sentences are of the same pattern. In addition, acceptability of the sluicing sentences is represented as a continuum depending on level of difficulty to link the sluice to its correlate. 
160 A Discourse Analysis Approach to the Sluicing Conundrum

language, but I don't remember which.

b. The administration has issued a statement that it is willing to meet with one of the student groups, but I am not sure which one.

c. That certain countries would vote against the resolution has been widely reported, but I am not sure which ones.

d. Sandy was trying to work out which students would be able to solve a certain problem, but she wouldn't tell me which ones.

e. Bob ate dinner and saw a movie that night, but he didn't say which.

f. It has been determined that somebody will be appointed; it's just not clear yet who.

The ensuing question is obviously why it is so. Since source sentences are unacceptable as in (16b)-(19b), the sluicing that comes after deletion is expected to be unacceptable if sluicing in (16a)(19a) were derived from the unacceptable source sentences in (16b)(19b). On the one hand, connectivity effects strongly support the claim that sluicing results from complete deletion of whole IP after derivation of complete structures of IP. On the other, sluicing demonstrates insensitivity to standard island constraints, which applies to any sort of overt movement. Here comes a sluicing conundrum: It looks like a result of movement and subsequent deletion as far as connectivity effects are concerned but it does not exhibit one of the most commonly accepted characteristics of movement, sensitivity to islands.

Regarding this, some studies in line with the PF deletion analyses take the view that deletion repairs violation. For instance, Lasnik (2001, 2005) and Merchant (2004) argue that ellipsis is PF deletion and that islands in (16)-(20) are all PF-islands whose violation can be repaired by PF deletion. If Chomsky (1972) is right in saying that * (or \# in Chomsky's presentation) is assigned to an 
island when it is crossed by movement, * gets deleted in tandem with other structures when it undergoes PF-deletion. Put differently, if a later operation deletes a category with violation, the derivation gets salvaged. Merchant (2001), on the other hand, proposes a heterogeneous theory of islands by classifying them into three. Islands of the first class are weak islands, which he claimed are not syntactic. The second class consists of PF islands, whose effects can be nullified by PF deletion. Finally, the third class involves extraction out of a propositional domain whose interpretive effects can be achieved by modal subordination and E-type anaphora. Apparent violations in propositional islands involve a syntactically different structure from other PF-islands: there is no island and therefore there is nothing to repair. Arguing against this claim on propositional islands, Lasnik (2001, 2005) provides non-trivial examples where putative sources for the sluice without an island seem to be impossible or cause other violations such as binding. Then the ensuing question is whether it is necessary to complicate the theory by assuming violation of a principle and subsequent salvation of the violation.

There is another approach to the sluicing conundrum, which does not assume any movement of the sluice from the beginning. Chung, Ladusaw, and McClosky (hereafter CLM) (1995) argue that the amelioration of island effects follows if interpretations of sluicing are derived by copying relevant portions at LF. If we do not assume any movement, lack of island violation would not be any problem since there was no movement at all. Therefore there is no crossing of islands. This line of approach, however, has the burden of proof to explain the connectivity effects, such as why the Case of the sluice is the same as its antecedent in the first conjunct, and why only those languages that have preposition stranding properties let the sluice be the bare object of a preposition. Another problem of an LF-copying approach arises from its identity condition. If LFcopying is based on LF syntactic identity, we face Binding Principle 
162 A Discourse Analysis Approach to the Sluicing Conundrum

C issues (or Fiengo and May's vehicle change issues (1994)) as in (21), modality discrepancy issues as in (22)-(23) as well as contrast sluicing issues as in (24) (Merchant 2001, 2005):

(21) a. They arrested Alex ${ }_{3}$, though he ${ }_{3}$ didn't know why.

b. * They arrested Alex $_{3}$, though he ${ }_{3}$ didn't know why [IP they arrested $\mathrm{Alex}_{3}$ ]

c. They arrested $\mathrm{Alex}_{3}$, though he ${ }_{3}$ didn't know why [IP they arrested $\operatorname{him}_{3}$ ]

(22) a. Decorating for the holiday is easy if you know how!

b. * Decorating for the holiday is easy if you know how [IP decorating for the holiday]

c. Decorating for the holiday is easy if you know how [IP to decorate for the holiday]

(23) a. I remember meeting him, but I don't remember when.

b. * I remember meeting him, but I don't remember when [IP meeting him]

c. I remember meeting him, but I don't remember when [IP I met him]

(24) a. She has five CATS, but I don't know how many DOGS.

b. * She has five CATS, but I don't know how many DOGS [IP she has five CATS]

c. She has five CATS, but I don't know how many DOGS [IP she has $\mathrm{x}$ ]

As we can see in (b) sentences of (21)-(24), if we strictly follow the isomorphism for copying an antecedent phrase in sluicing, we would not be able to account for acceptable sluicing illustrated in their (a) couterparts. (21c) demonstrates that we need to introduce pronouns 
instead of R-expressions to understand lack of Principle $\mathrm{C}$ violation. (22c) and (23c) necessitate generosity to allow certain inflectional mismatches (or more than that) between the antecedent clause and the elided one. Strict isomorphism would force an interpretation of (24a) as the one in (24b). However, there do not exist animals that are both dogs and cats.

\section{Local Extraction}

We have seen that sluicing constructions have apparently incompatible properties at the same time. Connectivity-wise, it seems to be formed by movement; Island sensitivity-wise, it does not behave like a result of movement. Our proposal starts with questioning whether it is necessary to assume the exactly same structure for the interpretation of the second conjunct in sluicing constructions. If we take the view that what ellipsis requires is not a syntactic identity but a semantic one such as mutual entailment, it is not necessary to complicate operations in sluicing by assuming violation and the undoing of the violation. We argue that apparent repairing phenomena of island effects arise from the fact that the sluice does not cross islands when it moves. If there is no violation, there is nothing to salvage.

More specifically, this paper assumes that ellipsis can occur if it satisfies mutual entailment requirements (Merchant 2001, 2005, Rooth 1992, Romero 1998, Schwarzchild 1999). Ellipsis is allowed without strict structural identity as far as e-givenness in the following is satisfied:

(25) E(lliptical) Givenness

An expression $\mathrm{E}$ counts as e-given iff $\mathrm{E}$ has a salient antecedent $\mathrm{A}$, and modulo $\exists$-type shifting,

a. A entails F-clo(E), and 
164 A Discourse Analysis Approach to the Sluicing Conundrum

b. E entails F-clo(A)

(26) F-closure

The F-closure of $\alpha, F-\operatorname{clo}(\alpha)$, is the result of replacing F(ocus)-marked parts of $\alpha$ with $\exists$-bound variables of the appropriate type (modulo $\exists$-type shifting).

(27) Focus condition on Ellipsis

An XP $\alpha$ can be deleted only if $\alpha$ is e-given.

If the deleted portion e-given, sluicing construction does not necessarily require that an island be manufactured in the second conjunct even when there is one in the first conjunct. Instead, we can assume there is a pronominal element, an E-type anaphor, that can convey the meaning of the given portion in the first conjunct. An E-type anaphor is defined as a definite description in which the property that determines its identity is recoverable from the context, according to Cooper (1979). They refer to anaphors that are neither referential nor bound as illustrated with italics in (28):

(28) a. Every girl who deserves $i t^{E-t y p e}$ got the prize she wanted.

b. Any man who loves a woman should respect $h e r^{E-t y p e}$.

It in (28a) is associated with 'the prize she wanted' and her in (28b) refers to 'the woman he loves'. In fact, there are many pieces of evidence showing the need of anaphoric elements in sluicing. For instance, each use of indefinite introduces a new discourse referent as in (29b) while sluicing with indefinite antecedent in (29a) does not:

(29) a. John asked where someone had committed a crime but he does not know when.

b. Someone committed a crime on Monday and 
someone committed a crime on Tuesday.

It is obvious that two different people are mentioned in (29b), while this is not the case in (29a). If (29a) had (30a) as its source, we would not have the same interpretation as for (29a). The second instance of someone in (30a) introduces a new discourse referent while there is only one referent for someone in (29a). This lead us to conclude that the source structure for (29a) is (30b) with a pronominal element.

(30) a. John asked where someone had committed a crime but he does not know when someone committed a crime.

b. John asked where someone had committed a crime but he does not know when he committed a crime.

Likewise, as Merchant (2001) points out, the following cases in (31), where IPs that contain A'-traces also license deletion of IPs, demonstrate that we need anaphoric elements for a proper interpretation of deleted IPs as in (32):

(31) a. Who did the suspect call and when?

b. The judge had records of which divers had been searching the wreck, but not of how long.

(32) a. Who did the suspect call and when did the suspect call him?

b. The judge had records of which divers had been searching the wreck, but not of how long they had been searching the wreck.

If introduction of pronominal elements is unavoidable for sluicing, there will not be any extra burden when we assume the 
166 A Discourse Analysis Approach to the Sluicing Conundrum

existence of anaphoric element in sluicing with apparent island violation constructions. As far as the E-givenness requirement is satisfied, putative sources of sluicing where apparently long distance extraction seems to have taken place can be analyzed as ones with local extraction. Consider: ${ }^{4}$

(33) a. I confirmed the rumor that Mary married someone important, but I haven't been able to find out who.

b. * I confirmed the rumor that Mary married someone important, but I haven't been able to find out who $I$ cenfirmed a rumer that she married.

c. I confirmed the rumor that Mary married someone important, but I haven't been able to find out who she married.

(33a) is an example from Baker and Brame (1972) where we need to postulate a local extraction of the sluice rather than long distance extraction even when the first conjunct has islands. So far, we have seen sluicing examples where pronominal expressions are needed independently from cases that demonstrate lack of island effects. ${ }^{5}$

\footnotetext{
${ }^{4}$ The supposedly elided portion of sluicing is indicated by strikethrough.

${ }^{5}$ Lasnik $(2001,2005)$ raises non-trivial issues against Merchant (2001)'s E-type pronoun approach to propositional island violations in sluicing and further claims that deletion repairs all sorts of island violations. One of his arguments against Etype pronouns is illustrated in the following case where a structure that includes the island must exist for licensing an item in the sluicing:

(i) a. Each of the linguists met a philosopher who criticized some of the other linguists, but I am not sure how many of the other linguists.

b. * How many of the other linguists did the philosopher criticize?
}

As we can see in (ib), the other will not be acceptable if there were no overt each postulated in the second conjunct. For this reason, Lasnik $(2001,2005)$ claimed that how many of the other linguists in (ia) is extracted crossing over islands and that there is repair of relative clause island violations in sluicing as in (iia). 
Returning to the main thread of this section, let us see what kind of putative sources we can assume for the cases causing the sluicing conundrum. First of all, let us see noun complement island examples from Ross (1969) and from CLM (1995) that we have discussed in (16) and (20) (repeated here for ease of reference):

(34) a. (??) I believe the claim that he bit someone, but they don't know who.

b. The administration has issued a statement that it is willing to meet with one of the student groups but I am not sure which one.

If (35) were the only way to express the given interpretation, then we might have to rely on an island violation repair strategy to account for the change of acceptability from (35) to (34). However, as we can see in (36), if we allow putative source sentences with structural variations and with the Cooper style analysis of E-type pronouns, we can produce desired interpretations of the sluicing wit local extraction:

(35) a. * I believe the claim that he bit someone, but they don't know who I believe [the claim that he bit].

However, if we employ the Cooper style analysis of E-type pronouns, desired interpretations of each and other in (ia) can be retrieved via short extraction as in (iib).

(ii) a. Each of the linguists met a philosopher who criticized some of the other linguists, but I am not sure how many of the other linguists [each of the linguists met [a philosopher [whocriticized $t]$ ].

b. Each of the linguists met a philosopher who criticized some of the other linguists, but I am not sure how many of the other linguists the philosopher who each of the linguists met criticized.

For more discussion on arguments that resolve the problems that Lasnik (2001, 2005) raised against the E-type pronoun approach, readers are referred to Kim (2006). 
168 A Discourse Analysis Approach to the Sluicing Conundrum

b. ?*The administration has issued a statement that it is willing to meet with one of the student groups but I am not sure which one [it has issued a statement that it is willing to meet with].

(36) a. (??) I believe the claim that he bit someone, but they don't know who I believe he claimed to bit.

b. The administration has issued a statement that it is willing to meet with one of the student groups but I am not sure which one it has stated that it is willing to meet with.

The second type of examples in Ross (1969) is one with relative clauses:

(37) a. (??) She kissed a man who bit one of my friends, but Tom doesn't realize which one of my friends. ((17) is repeated)

b. They want to hire someone who speaks a Balkan language, but I don't know which. ((20a) is repeated)

If we employ E-type pronouns as in (38), we can see how to derive interpretations of sluicing in (37) without complicating grammar by violating island constraints and undoing it: ${ }^{6}$

(38) a. (??) She kissed a man who bit one of my friends, but Tom doesn't realize which one of my friends $h e^{\mathrm{E}-\mathrm{type}}$ bit.

b. They want to hire someone who speaks a Balkan language, but I don't know which she $e^{\mathrm{E}-\mathrm{type}}$ should speak.

\footnotetext{
${ }^{6}$ Following Roberts (1989, 1996), Merchant argues for "modal subordination" for sluicing with subjunctive relative clauses as in (38b). He claimed that operator that the subjunctive in the relative clause provides licenses the modal subordination in the elided IP.
} 
Likewise, apparent sentential subject island violation demonstrated in (18) and (20c) can also be accounted for if we allow putative source sentences with structural variations:

(39) a. (??) That he'll hire someone is possible, but I won't divulge who.

b. That certain countries would vote against the resolution has been widely reported, but I am not sure which ones.

(40) a. (??) That he'll hire someone is possible, but I won't divulge who it is possible for him to hire.

b. That certain countries would vote against the resolution has been widely reported, but I am not sure which ones have been widely reported to vote against the resolution.

Finally, let us extend our discussion to coordinate structure islands illustrated in (19), repeated here as (41a).

(41) a. (??) Irv and someone were dancing together, but I don't know who.

b. * Irv and someone were dancing together, but I don't know who [Irv and $\mathrm{t}$ were dancing together].

c. Irv and someone were dancing together, but I don't know who [t was dancing together with Irv].

If (41b) were putative source for sluicing in (41a), we would face burden of explaining the difference in acceptability between them. Once we allow structural variation under the E-giveness requirement, however, apparently problematic coordinate structure violation in (41a) is also accounted for. In these cases again, we can provide a legitimate source sentence as (41c) without relying on the repair 
170 A Discourse Analysis Approach to the Sluicing Conundrum

strategy. $^{7}$

In this section, we have argued that we do not have to rely on unnecessary complication of a theory by assuming doing (i.e., island violation) and undoing (i.e., its repair) procedure in derivation of sluicing if we employ E-type anaphors in source sentences of sluicing. This way of treating sluicing would be more plausible than others in that nothing essential needs to be said beyond employing E-type anaphors which are independently required. If we can show that local extraction is a possible alternative for sluicing with islands, the burden of proof resides rather with those who complicated the theory with undoing procedure. In what follows, we will show that local extraction approach that we propose fares better empirically.

\section{Discourse Activation}

We have discussed cases of sluicing where acceptability status is improved compared to their apparently full-fledged counterparts. In fact, we have shown that they are only apparent because of possibility to postulate different putative sources which enable local extraction of the sluice. If it is the case, we would not expect unacceptability even when there are islands in the first conjunct. In this sense, one of the most interesting and theoretically challenging

\footnotetext{
${ }^{7}$ As illustrated in (41c), we need with to mark one of the conjuncts in this structure. At this point, it is worthwhile to note that sluicing examples that apparently violate the conjunction condition always contain expressions such as 'together' as in (41a). One can argue that a part of the second conjunct with with can be deleted if its semantic value is guaranteed by adverbial predicates like 'together' or 'jointly'. In fact, there has been some debate on the acceptability status of sluicing with coordinate structures in (41a). Ross (1966) marks them with ??, while Baker and Brame (1972) judge them ungrammatical. Those speakers who do not allow sluicing of this sort illustrated in (41a) may not allow deletion of with without its overt antecedent in the antecedent clause. -i.e., the antecedent clauses in (41a) contain and instead of with.
} 
cases is found in the following pair, where the correlate of the sluice is not explicit:

(42) * John sent Bill a picture that he painted, but it's not clear with what.

This seems to be a counterexample to the claim of this paper because if we employ E-type pronouns, (43) can be a potential source sentence which does not exhibit any island violation:

(43) John sent Bill a picture that he painted, but it's not clear with what $h e^{\mathrm{E}-\mathrm{type}}$ painted it.

Contrary to what is expected, acceptability of a sluicing version of (43) is severely degraded as if we need to take the PF-deletion analysis that we have argued against so far:

(44) * John sent Bill a picture that he painted, but it's not clear with what John sent Bill a picture that he painted.

Regarding this, CLM (1995) claim that sluicing with an implicit antecedent like (42), which they call sprouting cases, should be dealt with by an $\mathrm{A}^{\prime}$-chain formation operation and are predicted to behave parallel to other $\mathrm{A}^{\prime}$-chains that are created by overt movement as in (44). ${ }^{8}$ However, as we can see in (45), it is not necessarily the case that sluicing with implicit antecedent always shows island effects:

(45) a. *John sent Bill a picture that he painted, but it's not clear with what.

${ }^{8}$ CLM (1995) propose "sprouting" for sluicing with no overt correlate in the antecedent clause: that is, they hypothesize that implicit antecedents "sprout" in order to realize a trace that is needed to complete a wh-chain. 
172 A Discourse Analysis Approach to the Sluicing Conundrum

b. ok/?/??Tony sent Mo a picture that he had just painted, but it's not clear to her with what kind of brushes.

c. (Tony has been painting with two kinds of brushes badger-hair brushes and horse-hair brushes.) Yesterday, he showed Mary a picture that he had just painted, but he didn't tell her with which kind of brushes.

The antecedent clauses in (45) all have an implicit adjunct in a relative clause island. (45a) is unacceptable as noted by CLM, but (45b) is considerably better than (45a), and is acceptable to some speakers. Now, if the PF deletion approach is right in saying that (42) is unacceptable because of its source (44), then we can ask why there is acceptable sluicing as in (45c). However, if we argue that $(45 \mathrm{c})$ is acceptable because of local extraction without any island violation illustrated in (46), then we need to account for why the same logic does not apply to (45a):

(46) (Tony has been painting with two kinds of brushes badger-hair brushes and horse-hair brushes.) Yesterday, he showed Mary a picture that he had just painted, but he didn't tell her with which kind of brushes $h e^{\mathrm{E}-\text { type }}$ painted it.

This fact clearly suggests that the acceptability status of examples in (45) is not a syntactic fact, but is derived from some other part of grammar. What is also important to note here is that acceptability of sluicing sentences at issue is represented as a continuum depending on preceding discourse. Syntactic violations cannot be scaled as $30 \%$ or $50 \%$ violation since there are no $30 \%$ worth islands or 50\%-worth islands. Following Kim (2008) and Kim and Kuno (2010), we attribute the degree of un/acceptability 
illustrated in (45) is from the degree of ease or difficulty with which the hearer can recognize the presence of an implicit antecedent in the antecedent clause. With what in (45a) does not carry enough information for the hearer to recognize that it refers to an implicit instrumental adjunct of painted. In contrast, with what kind of brushes in (45b) helps the hearer realize that various types of brushes are at issue, and activates awareness of the implicit adjunct antecedent with a certain kind of brushes in the hearer's mind, albeit with a time delay. This time delay makes the sentence less than perfectly acceptable to most speakers, but it nevertheless contributes to making the sentence much more acceptable than (45a). When activation of the awareness of the implicit antecedents takes place prior to the appearance of the wh-remnant in discourse, sluicing results in perfect acceptability as shown in (45c). Observe that the leading statement in (45c) has activated in the awareness of the hearer the implicit antecedent of the remnant wh-expression (i.e., "(painting) with a certain kind of brushes"). ${ }^{9}$

In the above, we have shown that sentences involving implicit antecedents in islands are acceptable if the antecedents are activated in the awareness of the hearer by the contexts that precede them. The ensuing question is how and why discourse activation works as the way it works for the sentences in (45). We attribute the degraded difficulty of acceptability in (45a) to processing difficulty of the hearer. When the hearer encounters the sluice in the examples in (45), he/she looks for a prominent correlate in the preceding context. Prominency of the correlate is determined by many factors such as being overt, discourse activated, and not being in the islands. If there is any prominent correlate, it will take that option. The more

\footnotetext{
${ }^{9}$ (45b), the counter-example to CLM's generalization that we have given above, has a remnant that contains which - a $\mathrm{D}$ (iscourse)-linked wh-expression. Therefore, it might be argued that its acceptability is explainable by Pesetsky (1987)'s hypothesis that D-linked wh-expressions need not be raised at LF.
} 
174 A Discourse Analysis Approach to the Sluicing Conundrum

prominent the correlate is, the less processing load the parser carries. In the worst case like (45a), if a parser cannot find any candidates that satisfy requirements of being prominent, it fails to parse the sentence. Since prominency is a gradable concept, we see a continuum in the acceptability status of sluicing sentences in (45). What we have seen in this section supports the proposal in the previous section that local extraction will do even when the antecedent of the sluice is implicit. What matters in sluicing with implicit antecedents is whether the antecedent can be prominent enough for the hearer to parse it as a proper antecedent. If it is activated by preceding discourse, it fulfills the prominency requirement even if implicit. If it is not activated in the hearer awareness by any preceding discourse, then sentence will end up failing to be parsed.

\section{References}

Albert, C. 1993. Sluicing and Weak Islands. Ms. University of California, Santa Cruz.

Chomsky, N. 1993. A Minimalist Program for Linguistic Theory, in $\mathrm{K}$. Hale and S. J. Keyser (eds.) The View from Building $20-$ Essays in Linguistics in Honor of Sylvain Bromberger, 1-52. Cambridge, Mass.: MIT Press.

Chomsky, N. \& H. Lasnik. 1993. Principles and Parameters Theory, in J. Jacobs, A. von Stechow, W. Sternefeld, \& T. Vennemann (eds.) Syntax: An International Handbook of Contemporary Research, 506-70. Berlin: Mouton de Gruyter.

Chung, S., et al. 1995. Sluicing and Logical Form. Natural Language Semantics 3, 239-82.

. 2006. Sluicing Revisited. LSA Annual Meeting Symposyum on Ellipsis. New Mexico: Albuquerque.

van Craenenbroeck, J. 2007. What Lies Beneath: The Hidden 
Syntax of Sluicing. Talk given at New York University.

Condoravdi, C. \& J. Gawron. 1996. The Context-dependency of Implicit Arguments, in M. Kanazawa, C. J. Pinon., \& H. de Swart (eds.) Quantifiers, Deduction and Context. Stanford:

CSLI. [page numbers are missing]

Culicover, P \& Ray. J. 2005. Syntax Made Simple(r). New York: Oxford University Press.

Dalrymple, S., et al. 1991. Ellipsis and Higher-order Unification, Linguistics and Philosophy 14, 399-452.

Evans, G. 1980. Pronouns. Linguistic Inquiry 11, 337-62.

Fiengo, R., \& R. May. 1992. The Eliminative Puzzles of Ellipsis. In Proceedings of the Stuttgart Ellipsis Workshop, Steve, B. \& A, Hestvik (eds.) Heidelberg, Germany: Arbieitspapiere des Sonderforschungbereichs 340, Bericht Nr. 29.

Fodor, J. A., \& J. D. Fodor. 1980. Functional Structure, Quantifiers and Meaning Postulates. Linguistic Inquiry 11, 759-770.

Fortin, C. 2007. Indonesian Sluicing and the P-stranding Generalization. Paper presented at the 14th Annual Meeting of the Austronesian Formal Linguistics Association (AFLA14). Montreal: McGill University.

Fox, D. 2000. Economy and Semantic Interpretation. Cambridge, MA: MIT Press.

Fox, D. \& H. Lasnik. 2003. Successive Cyclic Movement and Island Repair: The Difference between Sluicing and VP Ellipsis. Linguistic Inquiry 34, 143-164.

Ginzburg, J. \& I, Sag. 2000. Interrogative Investigations: The Form, Meaning, and Use of English Interrogatives. Stanford, CA: Center for the Study of Language and Information.

Hardt, D. \& M. Romero. 2004. Ellipsis and the Structure of Discourse. Journal of Semantics 21, 375-414.

Hendricks, P. \& H. Hoop. 2001. Optimality Theoretic Semantics. Linguistics and Philosophy 24, 1-32.

Kennedy, C. \& J. Merchant. 2000. Attributive Comparative Deletion. 
176 A Discourse Analysis Approach to the Sluicing Conundrum

Natural Language and Linguistic Theory 19, 89-146. Kim, S.-Y. 2006. E-type Anaphora Will Do. Studies in Generative Grammar 16-4, 665-686.

. 2008. Islands in Sluicing with Implicit Antecedent. Korean Journal of Linguistics 33-4, 589-609.

. 2009. Questioning Assumptions for Scope Parallelism in

Sluicing. Studies in Generative Grammar 19-4, 529-548.

Kim, S.-Y. \& S. Kuno. 2010. Sluicing with Implicit Indefinites as Antecedents. Ms. Sejong University \& Harvard University.

Koopman, H. \& D. Sportiche. 1982. Variables and the Bijection Principle. Linguistic Review 2, 139-60.

Kuno, S. 1972. Natural Explanations for Some Syntactic Universals. Mathematical Linguistics and Automatic Translation, Report No. NSF-28 to the National Science Foundation, Harvard University, II-1-85.

Kuno, S. \& J. Robinson. 1972. Multiple Wh Questions. Linguistic Inquiry 3, 463-487.

Lakoff, G. 1972. A Note on Vagueness and Ambiguity (a squib). Linguistic Inquiry 1, 357-359.

Lasnik, H. 2001. When Can You Save a Structure by Destroying It? North East Linguistic Society 31, 301-320.

. 2007. On Ellipsis: the PF Approach to Missing Constituents. University of Maryland Working Papers in Linguistics 15, A. Conroy, C. Jing. C. Nakao, E. Takahashi (eds.), 143-153, College Park, MD.

Lobeck, A. 1991. The Phrase Structure of Ellipsis, in Susan Rothstein (ed.) Perspectives on phrase structure, 81-103. San Diego: Academic Press.

May, R. 1985. Logical Form - Its Structure and Derivation. Cambridge, MA: MIT Press.

Merchant, J. 2001. The Syntax of Silence: Sluicing, Islands, and Identity in Ellipsis. Oxford: Oxford University Press. . 2002. Swiping in Germanic, in C. Jan-Wouter Zwart and W. 
Abraham (eds.) Studies in Comparative Germanic Syntax, 289316. Amsterdam: John Benjamins. . 2003. Sluicing, in M. Everaert and H. van Riemsdijk (eds.) The Blackwell Companion to Syntax. London: Wiley Blackwell, 269-289.

2004. Fragments and Ellipsis. Linguistics and philosophy 27, 661-738.

van Riemsdijk, H. 1978. A Case Study in Syntactic Markedness: The Binding Nature of Prepositional Phrases. Dordrecht: Foris.

Romero, M. 1998. Focus and Reconstruction Effects in Wh-phrases. Amherst: University of Massachusetts dissertation.

Ross, R. 1969. Guess Who? In Papers from the Fifth Regional Meeting of the Chicago Linguistics Society. Ed. Robert I. Binnick, Alice Davidson, Georgia M. Green, \& Jerry L. Morgan, 252-86.

Wasow, T. 1972. Anaphoric Relations in English. Cambridge, MA: MIT dissertation.

Soo-Yeon Kim

Department of English Language and Literature Sejong University

78 Gunja-Dong, Gwangjin-Gu, Seoul, Korea 143-747

Phone: +82-2-3408-3634; Email: kimsy@sejong.ac.kr

Received Jun. 2010; Reviewed Jul. 2010; Revised version received Aug. 2010. 